\title{
Biotechnology in agriculture and food systems: an example of science and society at a crossroad
}

\begin{abstract}
Michael J. Burke
Emeritus Professor, Department of Horticulture, College of Agricultural Sciences, Oregon State University, Corvallis, Oregon 97331 USA

Abstract: Biotechnology applications in agriculture and food systems have placed science and society at a crossroad in North America, Europe and large parts of Asia. Revolutionary advances in the biological sciences, such as cloning and other genetic manipulations of plants, animals and microorganisms, open up avenues of discovery of unprecedented potential. Such revolutionary moments, however, have historically attracted resistance and opposition. Most recently, use of genetically modified organisms (GMO's) in food has spawned debate among scientists and attentive members of the public. This is not the first time that rapid advances in science and the results of scientific experimentation have generated controversy. One of the earliest crossroads between science and society occurred in the $16^{\text {th }}$ and $17^{\text {th }}$ centuries between scientists and the prevailing belief system. Well documented are the arguments by the established church against the works of Galileo Galilei (1564-1642), who postulated an astronomical system that was, not geocentric, but heliocentric. In those early times, the crossroad was clearly set between the proponents of scientific theory and established societal beliefs. So, with a long historical lens, the present day controversy over GMO's and biotechnology may be seen as an extension of a time worn historical process of scientific controversy. With a shorter historical lens, it may be seen as the aftermath of previous societal concerns over the use of nuclear power, over the irradiation of foods, and as the consequence of a growing mistrust of scientists, government officials, and corporate agriculture in the Western world. The concerns expressed are wide-ranging and objections are often strongly held. Objections to the applications of biotechnology range from 1)gene pollution of important world food crops and livestock, 2)concern over ownership of genes, 3)allergic reactions to engineered proteins, 4)industrialization of the food system, 5)corporate control in agriculture, to 6)the demise of local food systems. This paper will address the crossroad issues now prevalent in North America and relate these to biotechnology opportunities and concerns that may arise in the Arabian Gulf.
\end{abstract}

Key words: Biotechnology, Genetic manipulation, Food Systems, GMO.

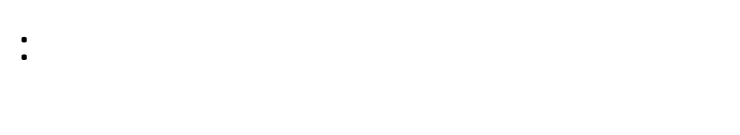

مايكل. ج. بيرك

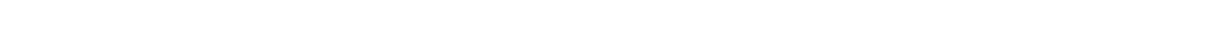

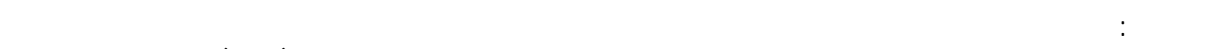

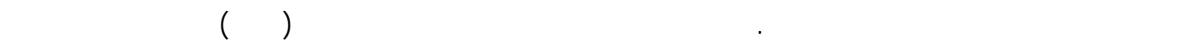

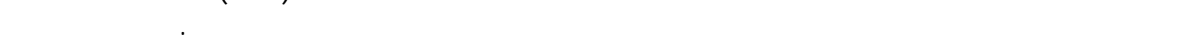



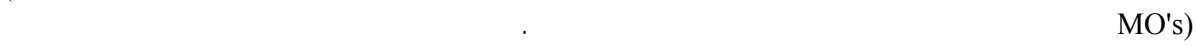

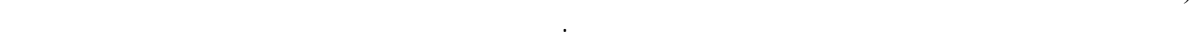



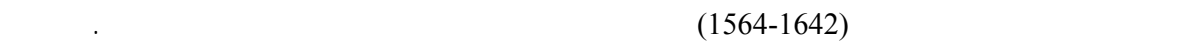

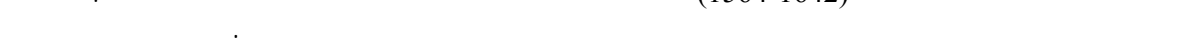

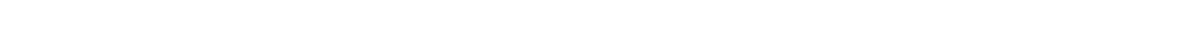

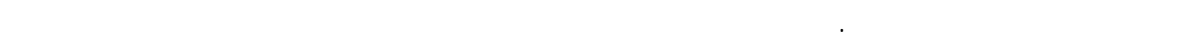

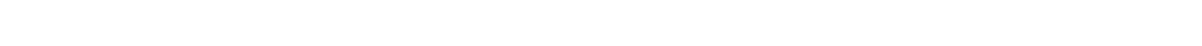

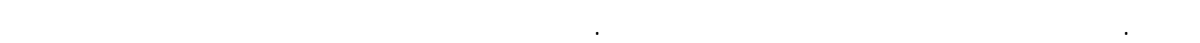

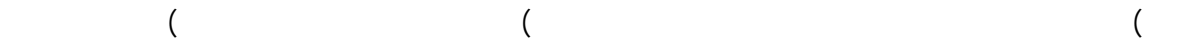




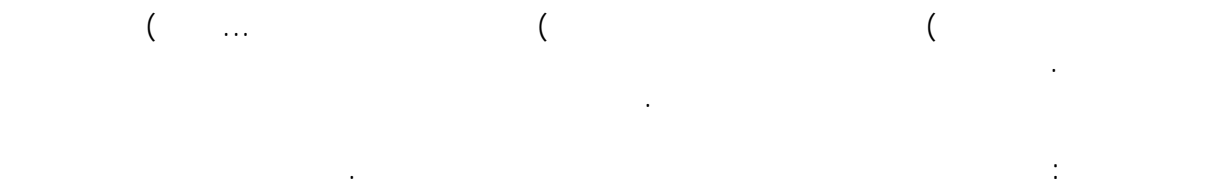

\section{Introduction}

\section{Biotechnology: A Crossroad between} Society and Science - Recently, new techniques applied to plant and animal reproduction, i.e., cloning and other genetic manipulations of plants, animals and microorganisms, have garnered public attention, sometimes even causing public alarm. Most recently, the application of biotechnology to agriculture in order to produce genetically modified organisms
(GMO's), has clearly juxtaposed the views of many contemporary scientists and segments of society. Not all scientists agree that the existence of these altered organisms is a positive development. As early as 1967, at least one of the early molecular biologists urged caution. The warning from the biophysicist Robert L. Sinsheimer is now part of the dedicatory art on the Molecular Biology building at Iowa State University (Figure 1):

\section{"Human Beings Are Not Yet Wise Enough To Direct The Course of Evolution."}

R. L. Sinsheimer, 1967

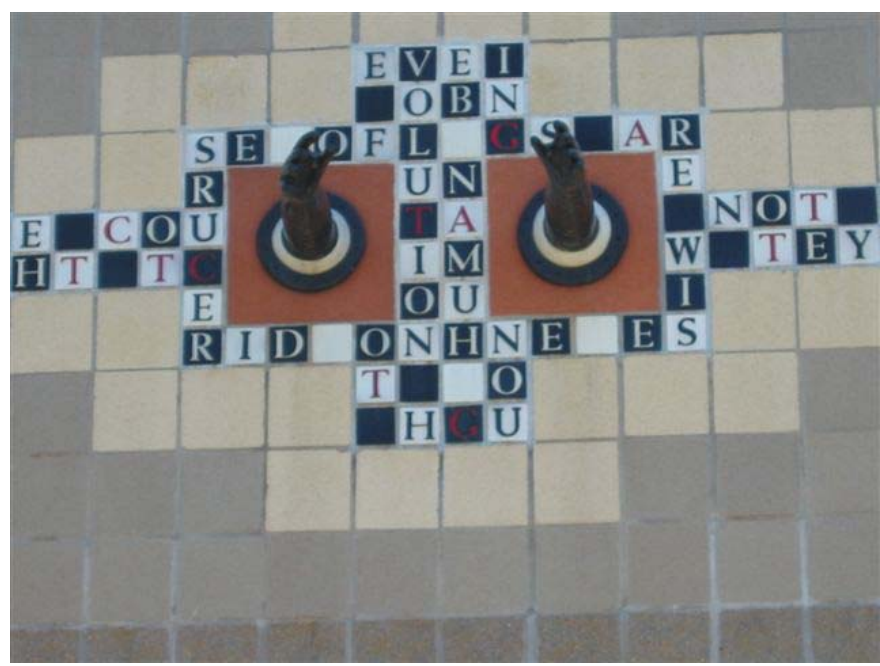

Figure 1. "Warning-Biohazard" by Andrew Leicester, Artwork on the north side of the Molecular Biology building at Iowa State University.

Sinsheimer, who was formerly a member of the Physics Department at Iowa State University, later did pioneering work on the bacteriophage $\varphi \mathrm{X} 174$ at the California Institute of Technology and was among the first molecular biologists. However, humans have long altered the course of crop and livestock "evolution" through selection of high performers and more recently the application of genetics. 
Norman Borlaug (2000), considered by many as the father of the green revolution, argues that society "must pursue agricultural biotechnology as a matter of humanitarian duty."

This is not the first time that rapid advances in science and the results of scientific experimentation have alarmed the public. History is once again repeating itself!

One of the earliest crossroads between science and society involved science and religion. Many in the contemporary scientific community compare the current controversy concerning genetic modification of organisms to those arguments put forth by the established church against the works of Nicolaus Copernicus (1473-1543) and later, Galileo Galilei (1564-1642), who postulated the astronomical system is heliocentric and not geocentric. Specifically, Galileo's sentence was heresy for teaching of a "sun centered world where the sun does not move where the earth is not at the center and does move." In those early times, the crossroad was clearly set between the proponents of scientific theory and religion. The Theory of Evolution promulgated by Charles Darwin (1809 -1882) once again placed science and the established church at a crossroad; and this crossroad certainly remains a challenge to the religious beliefs of many individuals to this day. Darwin addressed the question: Was the natural world a divine creation as described in the holy books or did it come into existence through an evolutionary process?

Interestingly, genetics, which has had great impact on agriculture and society, largely avoided public controversy in its early development. The founder of Genetics Gregor Mendel (1823-1884), the Augustinian priest, subtly avoided the opposition of Rome when he elucidated the basis of modern genetics. This was accomplished by working on pea plants and not animals (mice or bees). A premise of Mendel's work was that genetic inheritance originated from both paternal and maternal sources, then a controversial idea. Mendel's abbot suggested that he do his genetic experiments on peas and Mendel reportedly later recalled, "You see, that the bishop did not understand that plants also have sex" (Henig, 2000). In the earlier half of the twentieth century, Trofim Denisovich Lysenko (1898-1976), the Russian agronomist who co-discovered plant vernalization (ie. low-temperature promotion of flowering), led the movement to ban the teaching and practice of Mendelian genetics in the former USSR. Lysenko's belief that the genetic makeup is permanently changed by low-temperature treatment has been now completely dismissed by modern science. This related to political rather than religious issues. The eminent Russian crop geneticist and plant geographer, Nickolai I. Vavilov (1887 -1943) died in Saratov prison because of his opposition to Lysenko's pseudoscientific concepts and the resultant government policy, which held sway in the Stalinist purges prior to World War II. Interestingly, in the 1920's, the development of hybrid corn was a controversial subject in the United States, and was opposed by the Extension Services of some Midwestern Land Grant Universities.

The present day controversy over GMO's and biotechnology, however, may be more related to the aftermath of previous societal concerns over nuclear power, irradiation of foods, basic mistrust of scientists and government spokespersons and corporate agriculture. This was not helped when some governments said that eating meat from BSE (bovine spongiform encephalopathy) infected cows was safe. Unlike at earlier crossroads, the persons opposing the development of genetically modified organisms or other applications of 
biotechnology are not necessarily closely associated with an established church or the government. Their concerns are wideranging and objections are strongly held. Current objections to the applications of biotechnology include:

1. Gene pollution of important world food crops and livestock;

2. Gene flow through cross pollination between GM and non-GM crops;

3. Concern over GM virus resistant plants making new strains of viruses;

4. Cancer risks related to added DNA in genetically modified crops;

5. Introduction of allergens;

6. Ownership of genes;

7. Corporate resistance to labeling GM products restricting their "right to know;"

8. Industrialization of the food system;

9. Corporate control in agriculture; and

10. The demise of the family farm and local food systems.

Many attempts have been made to establish a dialogue between the probiotechnology and largely scientific community and those in society opposed to the applications of biotechnology in agriculture. One organization that has attempted to bridge the gap between the scientific community and concerned public is NABC (the National Agricultural Biotechnology Council). NABC proceedings are used extensively in this article.

\section{Discussion}

Promises of Biotechnology for Improving Food Systems - Up to this point biotechnology applications have focused primarily on crop improvements that benefit (most directly) the farmer. This involves use of a small number of "exotic" genes, generally of bacterial or virus origins that impart herbicide, insect and virus resistance to crop plants. An exception to this has been the development of "Golden" rice, which uses two daffodil genes and one bacterial gene to produce beta-carotene, which converts to Vitamin A in humans. Many more new genes are under investigation and these will provide the basis of the second generation of applications. Some of these will also benefit the farmer but others will have more direct benefit to the end consumer. I will address the latter group in this section.

Advances in genomics will help not only with an understanding of agricultural plants and animals but also with an understanding of humans and their varied and unique nutritional needs. With advances in the human genome and understanding human nutritional needs, better food products can be developed. This of course will require integration of research in food science and technology, dietetics and nutrition, medical science, and agriculture. This was the subject of the NABC 14 meeting titled "Foods for Health: Integrating Agriculture, Medicine and Food for Future Health" (Eaglesham et al., 2002).

High priority research areas identified at NABC 14 were nutritional approaches to alleviate the chronic diseases of obesity, heart disease, low birth weight children, and adult-onset (type 2) diabetes. The challenge to the research community is developing food and agricultural materials that are, for example, lower in fat, contain a higher proportion of omega-3 fatty acids, have increased anti-oxidant levels, contain essential minerals and amino acids, and have higher vitamin levels. Increasingly, such food products are called functional foods. The field is embryonic and underresearched. Examples of active research included the development of "Golden" rice with enhanced Vitamin A content. A GM Tomato has been developed with high anti- 
oxidant lycopene and lutein. Both of these have great potential in the developing world to help fight eye disease.

Another high priority area was research to understand food allergies and to develop allergen free foods. Some key human food allergies are from eggs, peanuts, milk, soybean, mustard, wheat, and shrimps. These allergens are proteins produced in the plant or animal. The allergen protein molecule must be large enough to give an IgE immune response but small enough to cross the gut membrane barrier. Molecular breeding approaches include posttranscriptional silencing, reduction of disulfide bonds and gene modification. In shrimps for example, the allergen is tropomyosin, which comprises $20 \%$ of the shrimp muscle protein and is essential for the shrimp's survival. The approach under investigation is first identification of the allergen protein $\operatorname{IgE}$ binding sites. Then, by amino acid substitution, the IgE binding regions are changed to make a new nonallergenic protein. Because the protein is important for the shrimp, the new protein must also be functional in the shrimp. Then lastly, the new protein gene is substituted back into the shrimp. A similar strategy is proposed for peanuts (Lehrer and Brannon, 2002). In cases where the protein is not essential for the plant or animal, the gene could simply be knocked out.

Human insulin has long been made from GM microbes by fermentation. Recently, a related area has developed and is attracting considerable research attention. It is called "Pharming" or using plants and animals to make pharmaceuticals. There are many examples. A company, Epicyte, has developed GM corn that produces antibodies that when topically applied prevent transmission of herpes simplex virus. Approaches are also being developed to make a number of antibodies for preventing organ transplant rejection. Further research is in the development of antibodies that recognize the beta amyloid proteins in Alzheimer's disease (Hein, 2002). Another company, Prodigene, has engineered corn to produce the egg protein avidin, which is used for medical diagnosis, and the industrial enzyme trypsin. There has been considerable research into the development of edible plant vaccines (e.g. Arntzen 2002) including vaccines for diarrhea. Prodigene is making an edible vaccine for Traveler's Disease, which results from an E. coli strain that produces an enterotoxin in humans. GM corn is used and the vaccine is effective in mice (Howard, 2002). Hiridin a human anticoagulant protein is produced commercially in canola in Canada.

There are advantages and challenges in producing pharmaceuticals in crop plants. The advantages are that food crops like corn and canola are very efficient in making large quantities of complex proteins. Usually less than about 400 hectares would be needed to provide the world's supply of a typical pharmaceutical. Plants have an advantage over animals in that plants produce no animal prions or pathogens that attach humans. Furthermore, food crops are known to be safe for human consumption, making them ideal for edible vaccines. However, there are some large challenges in using food crops for pharmaceuticals. So far the greatest is segregating the pharm crop from neighboring food crop fields and prevention of cross-pollination (gene flow) between food and pharm crops. Recently, Prodigene has been fined in the US for failing to control volunteer GM corn growing in a soybean fields in Nebraska. The volunteer corn came from one of Prodigene's earlier corn trials. This problem occurred a second time in a cornfield in Iowa (Hileman, 2003). As a result of these contamination problems, BIO (Biotechnology Industry Organization), 
which represents the major biotechnology companies in the USA, has issued a voluntary moratorium or growing pharm crops in food producing areas.

Promises of Biotechnology for Improving Agriculture in Regions with Extreme Environment - I will focus here on use of biotechnology for improving crop production in extreme environments because this is probably where the next wave of cropbiotechnology applications will occur. The environmental stresses of high salt, heat, drought, chilling and freezing have many common features when considered at the cell level. For example, plant cells must tolerate dehydration to survive salt, drought, heat and freezing stress. Salt dehydrates plant cells by osmotic withdrawal of the cell's water, in addition to the toxicity of excess ions. In drought and heat stress, the water evaporates. In freezing stress, the water freezes extracellularly. Therefore, cell tolerance of dehydration is a critically important factor and common to many plant environmental stresses. There are many other common factors, among these are high levels of sugars, increases in hydrophilic proteins and increases in the amino acid praline.

As an added note, plants are also very effective in avoiding or escaping environmental stress, and these are unusually accomplished at the whole plant level. These avoidance and escape mechanisms are usually unique for different stresses. For example, plants avoid salt by:

- Excluding salt uptake in the roots (salt levels increase in the root zone);

- Extruding extracellular salt using salt glands on the leaves (salt accumulates on the leaf surface);
- Diluting salt and holding extracellular water (plant parts thicken to hold the excess water);

- Sequestering salt in older leaves before they abscise (salty leaves drop to the soil);

- Sequestering excess salt in cell vacuoles where the salt may precipitate (associated with large plant cells)

These avoidance mechanisms are not common among different stresses and these mechanisms do not provide drought, freezing, chilling, and heat protection. Biotechnology approaches will probably be less effective in dealing with stress avoidance mechanisms (Levitt, 1980).

The advent of the recombinant DNA era ushered in optimism among plant biologists that more heat-, salt-, and droughttolerant plants would soon be developed. Identification of signaling genes that triggered plant responses to environmental changes heightened that optimism. As a result of significant breakthroughs, progress has been made in model plant systems and actual development of more hardy heat, salt, and drought tolerant crop plants has just begun. It is increasingly apparent that further progress will require integration of new knowledge from diverse research areas. These range from the biophysics to computational chemistry and proteomics. New sources of genetic diversity for extreme environment tolerance need to be identified. New knowledge of the multiple biological processes that confer environmental tolerance needs to be incorporated into diagnostic screens that can reliably identify alleles that are more tolerant. More efficient plant-breeding methods are needed to exploit discoveries in model microbial and plant systems. Progress has been substantial and scientists are optimistic that considerable progress will be made in the near future. 
A long-standing fundamental question is how plants perceive and respond to changes in their environment. We have some clues from rapid advances in our understanding of signal transduction. Advances are occurring in temperature, water and salt sensing and signal transduction components in bacteria. Histidine kinases have been identified as components in the perception of temperature signals in bacteria (Suzuki et al., 2000) and changes in membrane fluidity from temperature are implicated (Browse and Xin, 2001). In plants, signaling mediated by calcium changes (Sangwan et al., 2001) and calcium-responsive protein kinases have been identified (Zhu, 2001). Protein phosphatases have been demonstrated to be negative regulators of temperature acclimation responses (Tahtiharju and Palva, 2001). While temperature sensors are just starting to be studied in plants, temperature receptors and sensors have been identified in bacterial and animal cells (McKemy et al., 2002).

In addition to understanding sensing and signaling, understanding of the regulatory genes is advancing rapidly. Fortunately, Arabidopsis is an excellent model plant for study of underlying mechanisms of cold-, salt- and heat-tolerance in plants. Arabidopsis has a small compact genome of about 26,000 genes. It is a small plant and is easily grown in laboratory and greenhouse environments. The genome of Arabidopsis is now complete and there now is rapid postgenomic progress in finding multiple gene families involved in temperature, water and salt adaptation. Furthermore, findings with Arabidopsis can be readily transferred to important crop systems.

Very important have been the identification and characterization of many of the 1,500 transcriptional regulator genes (Riechmann et al., 2000). These transcriptional factors act as master switches and play key regulatory roles important for temperature, water and salt adaptation. They constitute $5 \%$ of the Arabidopsis genome code. Several of these transcription factors are now quite well characterized. They are important in the regulation of plant temperature adaptation. When overexpressed, two of these genes called CBF3 and CBF1 (also known as DREB1b and DREB1a, respectively) increase freezing, salt, and drought tolerance in nonacclimated as well as acclimated plants (Yamaguchi-Shinozaki and Shinozaki, 2001; Gilmour et al., 2000).

These CBF genes control multiple biochemical processes including the accumulation of total soluble sugars, proline, and coldregulated proteins (COR proteins). Many other processes associated with temperature adaptation are controlled by these genes. In Arabidopsis, overexpression of $\mathrm{CBF} 3$ can lead to low temperature hardiness of $-15^{\circ} \mathrm{C}$. This is well below the hardiness limit found naturally in Arabidopsis (Steponkus et al., 2000). Overexpression of CBF genes in canola gives similar results (Jaglo-Ottosen et al., 2000) and it is believed these genes will have great potential in other crop species. Clearly, these and other transcription factors act as master switches in plant regulation and they play an important role in plant temperature adaptation. They also play an equally important role in drought and salt adaptation and these effects can be transferred, to important crop species. Biotechnologists are just starting to exploit the temperature and salt-responsive transcription factors in new transgenic strategies to develop more tolerant crop plants.

QTL (quantitative trait loci) maps of winter hardiness for chromosome 7 of barley have a high degree of resolution. Interestingly, the CBF3 gene maps to the 
peak of the QTL map (Hayes, 2003). This further unites genetics and molecular biology.

Many other genes are important in plant stress adaptation and they are being characterized at a rapid rate. One example is the bacterial gene for choline oxidase that synthesizes the protectant chemical glycinebetaine. This gene confers increased temperature tolerance in transgenetic Arabidopsis. The increase in cold hardiness is found when the gene is expressed in the chloroplast (Sakamoto et al., 2000). Genes controlling vernalization, growth habit and floral induction in Arabidopsis alter flowering times, which are very important in the timing of temperature acclimation. These genes have important applications in crop improvement and can be used to change acclimation timing, vernalization, and even change winter to spring crops and vice versa (Schomburg et al., 2001). Overexpression of the anti-oxidant and free radical scavenging enzyme superoxide dismutase (SOD) has given substantial enhancement of temperature, drought, and salt hardiness of potato, canola and flax crops (Gusta, 2001).

Studies of the heat shock response have uncovered unexpected basic cell functions and united the study of protein folding with the function of several stress inducible proteins (Hendrick and Hartl, 1993). An evolution of thought beginning with the concept that high temperature resulted in protein denaturation, and leading to the realization that many heat shock proteins function as molecular chaperones in "assisted" protein folding and biogenesis has emerged in the last ten years. Manipulation of heat shock proteins that act as chaperones for protein folding holds potential for plant temperature and water stress protection (Queitsch et al., 2000; Wehmeyer and Vierling, 2000).
Biophysical aspects of temperature, water, and salt stress are now better understood. Common to many of these stresses at the cell level is cell dehydration. As water is removed from cells due to drought, heat, and osmotic (salt) conditions, many physical strains occur. These include membrane structural transitions, contacts between cell constituents, and protein/membrane denaturation. Sugars, proline, and other small molecules play an important protective role. Membrane and protein structural transitions are very important causes of damage.

A number of hydrophilic proteins protect plants from temperature, water and salt damage. Dehydrins and other late embryogenesis abundant (LEA) proteins have protective effects for drought stress (Ismail et al., 1999; Sivamani et al., 2000; Zhu et al., 2000).

In short, the field of temperature, salt, and drought stress in plants is very rich with opportunities for agriculture. Some of these opportunities come through conventional plant breeding and genetics. Some come through application of biotechnology. Most critical at this time is the work of "research teams" that can work at the molecular, cell, whole organism, and field levels. Such teams will benefit from inclusion of broad disciplinary scientific fields including plant breeding and genetics, agronomy, horticulture, botany, biochemistry and biophysics.

Biotechnology Applications of Relevance to the United Arab Emirates and the Gulf - Two areas come to mind as potential agricultural biotechnology research areas for the College of Food Systems at United Arab Emirates University.

The UAE is in a particularly good position to enter into research on the use of transgenetic plants for pharmaceutical 
production. First, the United Arab Emirates University has a fine medical school and excellent molecular biology facilities. The College of Food Systems will have the plant science faculty and students, processing facilities, and analytical equipment to conduct the needed plant biotechnology. The College of Engineering would be needed to help develop efficient extraction and processing approaches. UAE could produce the needed pharmaceutical crops in isolation from other food crops. This is not a small issue; take for example Prodigene isolation problems discussed earlier. Minimal irrigated land of perhaps 250 hectares might be sufficient. Less land would be necessary for trial plots. These could be among the highest value crops produced in the world if a successful industry were established. All of this would lead to a vertically integrated production and processing system with an end product of very high value indeed.

A second area where UAE has a relative advantage is plant salt, heat, and drought stress research. Biotechnology in these areas is advancing rapidly worldwide. Initial work would have to be more fundamental in nature but applications could be sought particularly for development of ornamental crops able to utilize less water and/or more saline irrigation water. Again, the college of Food Systems will have the facilities and expertise and the university will have the needed molecular biology capability.

The United Arab Emirates University brings some other advantages to the table. Mary Clutter of the US National Science Foundation talks about six major barriers for science in the $21^{\text {st }}$ century. These are boxology, broadening participation, reshaping education, public perceptions, infrastructure, and funding. Boxology refers to the departmentalization so prevalent in western universities. The science of the future will be more integrative, particularly the science of biotechnology. Broadening participation refers to people diversity issues that must be addressed in counties like the USA. UAE will also have to address some of these issues. Reshaping education is needed to produce the more broadly educated and technically able scientist of the future. This is what the new College of Food Systems will accomplish! Public perceptions and public acceptance of agricultural biotechnology is a problem that will have to be overcome in many parts of the world, particularly the EU counties, the USA, and Japan. Will this be as much of a concern in the UAE and the Gulf? The last two infrastructure and funding are related. The UAE is a wealthy country and it has made a major commitment in establishing the College of Food Systems and fine medical and engineering schools.

In concluding, Clutter notes that the science of the $21^{\text {st }}$ century will not be done in a vacuum and those who take advantage of "global intelligence" will advance most rapidly (Clutter, 2003). In short, the College of Food Systems will have to work on a world stage.

\section{Conclusion}

In summary, some applications of biotechnology in agriculture have attracted resistance and opposition by some members of the public in Europe, North America and Asia. There is considerable evidence for this resistance in the current news. The EU is requiring labeling and traceability (farm to fork) of GM foods. This is the basis of a WTO rule challenge suggesting it is as an unfair trade barrier. Major food manufactures and supermarkets in Europe, like Kellogg's, Tesco, and Unilever, are not selling biotech products. In the USA, Hershey Foods will not accept biotech sugar beets. McDonald's will not buy GM potatoes 
(Hileman, 2003). Zambia recently rejected US corn food-aid over concern that the corn would contaminate locally produced corn and jeopardize Zambia's export market. Thailand, Kenya and other developing countries may also be forced out of GM crop production because of potential loss of export markets (Knight, 2003). Finally, the 18 member Pew Initiative on Food and Biotechnology failed to bring consensus around biotechnology issues after 60 meetings, although there was limited progress (Knight, 2003). These current events must be considered when initiating biotechnology applications in agriculture and food systems. This has happened before when there are revolutionary advances in science.

At the same time, biotechnology holds great promise to improve the nutritional value of the foods we eat, leading to enhanced human health. To this point, the area is under-researched but a beginning has occurred. Promising examples include increases in vitamins and nutrients and removal of food allergens. Other examples involve plants engineered to produce biobased products like pharmaceuticals, edible vaccines, and industrial enzymes. Conclusively, biotechnology holds great promise to help local farmers produce more food in extreme environments with less input and environmental degradation. As outlined above, some of these applications may be relevant to the UAE.

There is hope that the second generation of biotechnology applications will be less controversial than the first. In a recent Policy Forum in Science magazine, Steven Strauss argued that the next generation of transgenic genes would be the crop's own genes (Strauss, 2003). He calls these genomicsguided transgenes and the process he describes is much more similar to conventional plant breeding. In place of the exotic genes of the first generation, a crop's own genes and those of near relatives would be used. One must be optimistic that the promises of food and agricultural biotechnology will be realized and improve the competitiveness and sustainability of the world's food system.

\section{Acknowledgment}

I would like to thank the staff of the Bamfield Marine Science Center, British Columbia, Canada for making their library available to me through the writing of this paper. I would also like to thank the meeting organizers for all the help they have provided in conducting this international conference on food systems.

\section{References}

Arntzen, C. 2002. Technology Progression in Plants Used for Food and Medicine, In: pp 175-180. pp 43-50. NABC Report 14 on Foods for Health: Integrating Agriculture, Medicine and Food for Future Health. National Agricultural Biotechnology Council, Ithaca, NY.

Borlaug, N. 2000. Ending world hunger: the promise of biotechnology and the threat of antiscience zealotry. Plant Physiology 124:487-90.

Browse, J. and Z. Xin. 2001. Temperature sensing and cold acclimation, Current Opinion in Plant Biology 4: 241-246.

Clutter, M. 2002. Supporting Comprehensive Foods for Health Research: A New Model, In: In: Eaglesham A, C. Carlson, and R. W. F. Hardy (Eds). pp 175-180. NABC Report 14 on Foods for Health: Integrating Agriculture, Medicine and 
Food for Future Health. National Agricultural Biotechnology Council, Ithaca, NY.

Eaglesham, A., C. Carlson and R. W. F. Hardy. 2002. NABC Report 14 on Foods for Health: Integrating Agriculture, Medicine and Food for Future Health, National Agricultural Biotechnology Council, Ithaca, NY, pp 342.

Gilmour, S. J., A. M. Sebolt, M. P. Salazar, J. D. Everard and M. F. Thomashow. 2000. Overexpression of the Arabidopsis CBF3 transcriptional activator mimics multiple biochemical changes associated with cold acclimation, Plant Physiol. 124: 1854-1865.

Hein, M. B. 2002. Supplementing the Immune System with Plant Produced Antibodies, In: In: Eaglesham A, C. Carlson, and R. W. F. Hardy (Eds). In: Eaglesham A, C. Carlson, and R. W. F. Hardy (Eds). NABC Report 14 on Foods for Health: Integrating Agriculture, Medicine and Food for Future Health. National Agricultural Biotechnology Council, Ithaca, NY.

Hendrick, J. P. and F. U. Hartl. 1993. Molecular chaperone functions of heatshock proteins. Annu. Rev. Biochem. 62: 349-384.

Henig, R. M. 2000. The Monk in the Garden: The Lost and Found Genius of Gregor Mendel, The Father of Genetics", Houghton Mifflin, Boston.

Hileman, B. 2003. Clashes Over Agbiotech, C\&EN, pp 25-33, June 9.

Howard, J. A. 2002. The Role for Edible Vaccines, In Eaglesham A, C. Carlson, and R. W. F. Hardy (Eds)., pp 153-166. NABC Report 14 on Foods for Health: Integrating Agriculture, Medicine and Food for Future Health. National Agricultural Biotechnology Council, Ithaca, NY.

Ismail, A. M. and A. E. Hall. 1999. Close TJ, Allelic variation of the dehydrin gene co segregates with chilling tolerance during seedling emergence. PNAS 96:13566-13570.

Jaglo-Ottosen, K. R., R. Kirstan, S. J. Gilmour and M. F. Thomashow. 2000. Role of Arabidopsis CBF regulatory genes in plant cold acclimation, Plant Physiology Supplement 13001.

Knight, J. 2003. Trade War Looms As US Launches Challenge Over Transgenetic Crops. Nature 423: 369 and 574.

Lehrer, S. B. and G. A. Brannon. 2002. Can we have Allergen Free Foods?, In: Eaglesham A, C. Carlson, and R. W. F. Hardy (Eds). pp 143-152. NABC Report 14 on Foods for Health: Integrating Agriculture, Medicine and Food for Future Health. National Agricultural Biotechnology Council, Ithaca, NY.

Levitt, J. 1980. Responses of Plants to Environmental Stresses, second edition, Academic Press, N. Y., p 497.

McKemy, D. D., W. M. Neuhausser and D. Julius. 2002. Identification of a cold receptor reveals a general role for TRP channels in thermosensation. Nature 7:52-58.

Queitsch, C., S. W. Hong, E. Vierling and S. Lindquist. 2000. Heat shock protein 101 
plays a crucial role in thermotolerance in Arabidopsis, Plant Cell 12:457-460.

Riechmann, J. L., J. Heard, G. Martin, L. Reuber, C. Z. Jaing, J. Keddie, L. Adam, O. Pineda, O. J. Ratcliffe, R. R. Samaha, R. Creelman, M. Pilgrim, P. Brown, J. Z. Zhang, D. Ghandehari, B. K. Sherman and C. L. Yu. 2000. Science 290:21052110 .

Sakamoto, A., R. A. Valverde, T. H. H. Chen and N. Murata. 2000. Transformation of Arabidopsis with the cod A gene for choline oxidase enhances freezing tolerance of plants. Plant J. 22:449-453.

Sangwan, V., I. Foulds, J. Singh and R. S. Dhindsa. 2001. Cold-activation of Brassica napus BN 115 promoter is mediated by structural changes in membranes and cytoskeleton and requires $\mathrm{Ca}^{2+}$ influx. Plant J. 27: 1-12.

Schomburg, F. M., D. A. Patton, D. W. Meinke and R. M. Amasino. 2001. FPA, a gene involved in floral induction in Arabidopsis, encodes a protein containing RNA-recognition motifs. Plant Cell 13: 1427-1436.

Sivamani, E., A. Bahieldin, J. M. Wraith, T. Al-Niemi, W. E. Dyer, T. H. D. Ho and R. Qu. 2000. Improved biomass productivity and water use efficiency under water deficit conditions in transgenetic wheat constitutively expressing the barley HV A1 gene, Plant Science 155:1-9.

Steponkus, P. L., A. Leipham, R. A. Fleck and R. Langis. 2000. Overexpression of DREB1a results in a prodigious increase in the freezing-tolerance of Arabidopsis thaliana, Plant Physiology Supplement 13002 .

Strauss, S. H. 2003. Genomics, Genetic Engineering and Domestication of Crops. Science 300: 61-62.

Suzuki, I., D. A. Los, Y. Kanesaki, K. Mikami and N. Murata. 2000. The pathway for perception and transduction of low-temperature signals in Synechocystis, EMBO J. 19: 1327-1334.

Tahtiharju, S. and T. Palva. 2001. Antisense inhibition of protein phosphatase 2C accelerates cold acclimation in Arabidopsis thaliana. Plant J. 4:461470.

Wehmeyer, N. and E. Vierling. 2000. The expression of small heat shock proteins in seeds responds to discrete developmental signals and suggests a general protective role in desiccation tolerance. Plant Physiol. 122:1099-1108.

Yamaguchi-Shinozaki, K. and K. Shinozaki. 2001. Improving plant drought, salt, and freezing tolerance by gene transfer of a single stress-inducible transcription factor, NOVARTIS Foundation Symposium 236:176-189

Zhu, J. K. 2001. Cell signaling under salt, water and cold stresses, Current Opinion in Plant Biology 4: 401-406.

Zhu, B., D. W. Choi, R. Fenton and T. J. Close. 2000. Expression of barley dehydrin multigene family and the development of freezing tolerance. Molecular and General Genetics 264:145-153. 